\title{
Thiol methyltransferase activity in inflammatory bowel disease
}

\author{
W E Roediger, W J Babidge
}

\begin{abstract}
Background-Luminal anionic sulphide may contribute to epithelial damage in ulcerative colitis. Thiol methyltransferase (TMT) governs sulphide detoxification by the colonic mucosa and circulating erythrocytes.

Aims-To measure levels of TMT activity in erythrocytes of surgically treated cases of colitis or in rectal biopsies of defined groups of colitis.

Patients-Venepuncture blood was obtained from 37 blood donors and 27 subjects who had previously undergone a proctocolectomy for colitis: 18 for ulcerative colitis and nine for Crohn's colitis. Rectal biopsies from 122 cases were obtained: 47 without mucosal disease, 33 post-colon resection for cancer, 14 with moderate to severe ulcerative colitis, 15 with quiescent ulcerative colitis, seven with acute Crohn's colitis, and six with radiation proctitis.
\end{abstract}

Methods-TMT activity was measured by high performance liquid chromatography with radioactive detection to measure ${ }^{14} \mathrm{C}$ methylmercaptoethanol formation, the reaction product of cell extracts incubated with mercaptoethanol and ${ }^{14} \mathrm{C}$ S-adenosylmethionine.

Results-Erythrocyte TMT activity of surgically treated cases of colitis was significantly elevated $(p<0.001)$ compared with control cases. TMT activity of rectal biopsies was significantly decreased $(p<0.02)$ in acute but not quiescent ulcerative colitis, Crohn's colitis, or radiation colitis.

Conclusions-Erythrocyte TMT activity was persistently elevated after proctocolectomy for Crohn's disease and ulcerative colitis. No primary defect of TMT activity was found in any case of unoperated colitis but mucosal activity was diminished with disease progression of ulcerative colitis. Studies of genetic control of TMT activity of erythrocytes in inflammatory bowel disease appear worthwhile.

(Gut 2000;47:206-210)

Keywords: thiol methyltransferase; hydrogen sulphide; methylation; ulcerative colitis; Crohn's disease

Professor W E W Roediger, Department of Surgery, Queen Elizabeth Hospital, 28 Woodville Road, Woodville South SA 5011, Australia. Email: wroediger@

medicine.adelaide.edu.au

Accepted for publication 22 February 2000

Bacterially produced hydrogen sulphide may play an intermediary role in the pathogenesis of ulcerative colitis (UC). In support are observations of increased rates of sulphide production from stool samples of colitis sufferers ${ }^{12}$ com- pared with control cases and increased luminal levels of sulphide in colitis, ${ }^{34}$ although rectal dialysis, a poor reflector of luminal sulphide production, did not show elevated levels of sulphide in colitis. ${ }^{5}$ Hydrogen sulphide impairs fatty acid oxidation in colonocytes, ${ }^{67}$ the chief energy substrate of these cells, and with increasing concentration also diminishes glucose oxidation. ${ }^{8}$ Decreasing the formation of sulphide in the colon by therapy with sulphasalazine, ${ }^{49}$ bismuth salts, ${ }^{9-11}$ or by decreasing sulphur amino acid intake ${ }^{12}$ produced treatment benefit for microscopic and UC patients. A low sulphate diet in patients with UC reduced bacterial sulphide formation. ${ }^{13}$

Despite evidence in support of sulphide in the causation of colitis, sulphide instilled in fractionated doses into the colon did not produce colitis ${ }^{14}$ although sulphide enhanced epithelial cell turnover in colonic biopsies. ${ }^{15}$ In contrast, continuous infusion of sulphide produced mucosal damage. ${ }^{16}$ Sulphide enhanced the oxidative burst of activated immune cells ${ }^{17}$ and stimulated release of nitric oxide from nitric oxide carriers ${ }^{18}$ thus placing sulphide in an intermediary category as a damaging agent to the colonic mucosa.

Protection against cellular damage by sulphide results from methylation of sulphide to less toxic methyl derivatives. ${ }^{19}$ Methylation is governed by a supply of the methyl donating agent S-adenosylmethionine (SAM), ${ }^{20}$ availability of ATP, and the activity of the methylating enzyme thiol methyltransferase (TMT) which is greater in the colonic mucosa than in the liver. ${ }^{21}$ Circulating red blood cell activity of TMT is elevated in cases of UC compared with controls. ${ }^{22}{ }^{23}$ Levels of TMT activity in rectal biopsies of UC have been reported as normal. ${ }^{24}$ The aim of the present study was to measure TMT activity in erythrocytes of cases who had undergone proctocolectomy for colitis and who were off medication for colitis and therefore free of bias from medication. TMT activity was also measured in rectal biopsies in defined groups of colitis where disease activity was carefully documented. The present results were compared with those previously reported.

\section{Patients and methods}

PATIENTS

Approval to conduct the study was obtained from the Ethics of Human Research Committee of the Queen Elizabeth Hospital and University of Adelaide.
Abbreviations used in this paper: $\mathrm{CD}$, Crohn's disease; SAM, S-adenosylmethionine; TMT, thiol methyltransferase; UC, ulcerative colitis. 
Table 1 Cases who underwent rectal biopsies for measurement of thiol methyltransferase (TMT) activity

\begin{tabular}{llll}
\hline Condition & No & Females: Males & Age (mean (SEM)) \\
\hline Benign colonic conditions & 47 & $23: 24$ & $65.3(1.8)$ \\
Treated colonic cancer & 33 & $18: 15$ & $70.7(1.8)$ \\
Acute ulcerative colitis & 14 & $6: 8$ & $44.1(3.9)$ \\
Quiescent ulcerative colitis & 15 & $6: 9$ & $47.9(6.5)$ \\
Acute Crohn's colitis & 7 & $2: 5$ & $33.4(3.4)$ \\
Radiation proctitis & 6 & Males only & $73.3(4.0)$ \\
\hline
\end{tabular}

For measurement of TMT activity in erythrocytes, patients were recruited from the Ileostomy Association of South Australia and blood samples for comparative purposes were obtained from the Blood Transfusion Services of South Australia, although these subjects did not have a proctocolectomy. Venepuncture samples were obtained in the non-fasting state during the morning and collected in lithium heparin. All UC patients had a total proctocolectomy with a Brooke's type terminal ileostomy and none was receiving steroids or sulphasalazine. None of the subjects had smoked for at least 10 years. There were 18 patients, 11 females and seven male, aged 36-86 years (mean 60.4 (SEM 3.4)) who had undergone their operation 2-50 (mean 18.4 (SEM 2.9) years ago. There were nine patients, six females and three males, who had a proctocolectomy and Brooke's ileostomy for Crohn's colitis, aged 21-80 (54.8 (6.7)) years, with their operation 6-37 (16.6 (3.7)) years ago. Three of the patients had small bowel resections of less than $30 \mathrm{~cm}$ and none was receiving sulphasalazine or steroids or had active Crohn's disease. There were 37 control cases, 18 females and 19 males, aged 39-68 (52.8 (1.1)) years and none was receiving steroids or sulphasalazine.

For measurement of TMT activity in the colonic mucosa, biopsies in all cases were obtained at colonoscopy $10-15 \mathrm{~cm}$ from the anal verge by means of Pauldrach biopsy forceps. Four biopsies with a combined wet weight of 17-29 mg were pooled for measurement of enzyme activity. Six groups of patients were studied and all had complete colonoscopies (table 1). Ages between the various colitis groups were not significantly different but ages between the control groups (benign and malignant) were significantly different $(\mathrm{p}<0.001$, Student's $t$ test) from the colitis groups. However, there are no reports to suggest that mucosal TMT activity varies with age. There was no significant difference in the sex distribution in any group. Benign conditions were either haemorrhoids, irritable bowel syndrome, or cases who requested colonoscopy to exclude bowel cancer. Cases of treated colonic cancers had resections more than 12 months previously and were undergoing surveillance colonoscopies. All cases of acute colitis histologically based on the Truelove and Richards criteria ${ }^{25}$ had moderate to severe colitis and all biopsies were taken from the involved area of mucosa. The proximal extent of the disease varied but all had rectosigmoid involvement. Cases of quiescent colitis were clinically and histologically in remission. Cases of Crohn's colitis had active disease. All acute colitis cases were receiving steroids and sulphasalazine and quiescent cases sulphasalazine or mesalazine only. Cases of mild to moderate radiation proctitis were men who had received radiation therapy for carcinoma of the prostate at least three years previously.

To compare TMT levels of mucosal biopsies with levels of isolated colonocytes, tissues were collected, as previously described, ${ }^{6}$ from the same colonic resections and biopsies taken adjacent to where mucosal strips were obtained to prepare isolated colonic epithelial cells. Such a comparison was done because biopsies as a composite tissue may have different TMT activity than isolated colonocytes.

\section{METHODS}

Erythrocyte membranes were prepared using a modification of the method of Pazmino and Weinshilboum. ${ }^{26}$ Blood $(20 \mathrm{ml})$ collected into lithium heparin was centrifuged at $800 \mathrm{~g}$ for 10 minutes. Plasma was removed and an equal volume of normal saline added. Following gentle mixing, recentrifugation at $800 \mathrm{~g}$, the procedure was repeated. After removal of plasma, ice cold distilled water $(20 \mathrm{ml})$ was added and the mixture centrifuged at $13000 \mathrm{~g}\left(4^{\circ} \mathrm{C}\right)$ for 10 minutes. The supernatant was discarded and the pellet washed carefully with $3 \mathrm{ml}$ Tris $\mathrm{HCl}$ buffer, $\mathrm{pH}$ 7.4. After the final wash, $6 \mathrm{ml}$ of Tris buffer were added before recentrifugation. The pellet was reconstituted with $120 \mathrm{ml}$ of Tris buffer before storage at $-80^{\circ} \mathrm{C}$. Prior to assay the mixture was sonicated on ice for about 10 seconds until homogeneous.

Colonocytes were prepared as described previously ${ }^{6}$ from resected segments of colon uninvolved with pathological change. Dithiothreitol was omitted in the preparation. Colonocytes, after isolation, were washed twice in $0.1 \mathrm{ml}$ dipotassium hydrogen orthophosphate $/ 1 \mathrm{mM}$ EDTA ( $\mathrm{pH} 7.4$ ) then ground finely in liquid nitrogen using a mortar and pestle.

Colonic mucosal biopsies which had been collected into preweighed tubes were kept on ice prior to isolating microsomes. The biopsy weight was calculated and $300 \mu \mathrm{l}$ of $0.25 \mathrm{M}$ sucrose added. This mixture was homogenised on ice and removed prior to washing the vessel with a further $200 \mu \mathrm{l}$ of $0.25 \mathrm{M}$ sucrose. This mixture was centrifuged at $12000 \mathrm{~g}\left(4^{\circ} \mathrm{C}\right)$ for 15 minutes. The supernatant was removed to another tube which was centrifuged at $105000 \mathrm{~g}\left(4^{\circ} \mathrm{C}\right)$ for one hour. The supernatant was removed and the pellet reconstituted in $200 \mu \mathrm{l}$ Tris buffer prior to freezing at $-80^{\circ} \mathrm{C}$. The mixture was sonicated as above.

TMT assays were performed on the supernatant fraction of biopsies, colonocyte suspensions, or entire suspensions of erythrocyte membranes. Prior to assay protein concentrations of samples were determined according to the method of Lowry and colleagues. ${ }^{27}$ TMT activity was determined by a modification of the method of Pazmino and Weinshilboum ${ }^{26}$ as outlined in detail previously. ${ }^{28}$ The HPLC system was not changed ${ }^{28}$ but the mobile phase was altered to $20 \%$ methanol $/ 80 \%$ distilled water with $1.75 \mathrm{ml} / \mathrm{l}$ dibutylamine in $20 \%$ phosphoric acid, $\mathrm{pH}$ 3. This mobile phase 


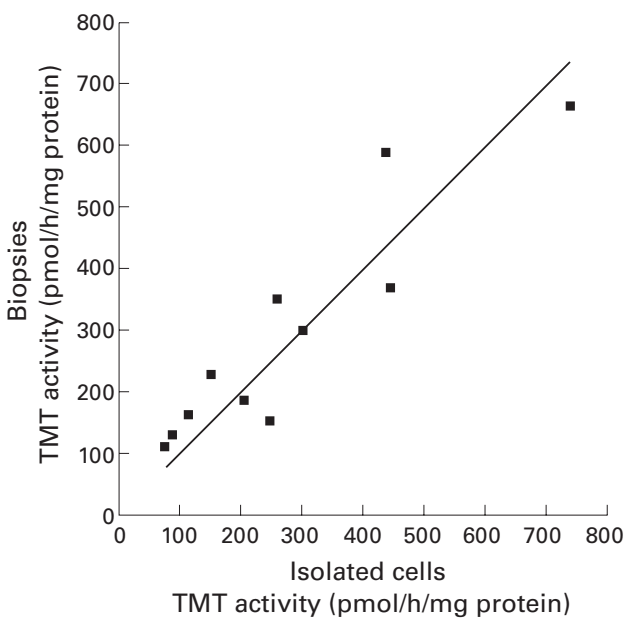

Figure 1 Thiol methyltransferase (TMT) activity of biopsies and isolated colonocytes prepared from the same colons $(n=11)$. Correlation coefficient of $r=0.92$, significance $p<0.001$, and regression line as indicated suggest equatable results with either tissue form.

eluted unused ${ }^{14} \mathrm{C}$ SAM as a large peak prior to ${ }^{14} \mathrm{C}$ methylmercaptoethanol and there appeared to be no problems with increased background radioactivity.

TMT activity was calculated as pmol of mercaptoethanol formed. The peak area $(\mu \mathrm{V}-$ seconds) was converted to disintegrations per minute (dpm) after determining a conversion factor by injecting a known amount of ${ }^{14} \mathrm{C}$ SAM and relating area to dpm. The specific activity of SAM was then used to calculate pmol of methylmercaptoethanol formed and results expressed as $\mathrm{pmol} / \mathrm{hour} / \mathrm{mg}$ protein.

STATISTICS

Analysis of variance (ANOVA) and Wald's test were applied in comparing results of multiple groups of patients. The Student's $t$ test for unpaired samples was also used to test the null hypothesis between groups and $p$ values $<0.05$ were considered significantly different.

\section{Results}

The within assay coefficient of variation of TMT activity was $7 \%$ and between assay was $6.4 \%$, with a minimal detection rate of $2 \mathrm{pmol} /$ hour/mg protein, as previously described. ${ }^{25}$ Comparison of TMT activity in isolated colonic epithelial cells with rectal biopsy samples of the same tissue specimen revealed a mean (SEM) value of $277.9(59.5)(n=11)$ for isolated cells compared with 293.35 (55.7) $(n=11)$ for biopsies. A linear relationship was found between the two tissue samples (fig 1) with a correlation coefficient of $0.92(p<0.001)$ between the two modes of tissue sampling. These results indicate that biopsy values closely reflect TMT activity of isolated colonocytes.

Values of TMT activity of erythrocyte membranes (fig 2) varied in healthy subjects with an intact colon (13-222 $\mathrm{pmol} / \mathrm{hour} / \mathrm{mg}$; mean (SEM) $120.00(9.6)(n=37))$. Values in colectomised cases of UC varied between 130 and $334.0 \mathrm{pmol} /$ hour $/ \mathrm{mg}$ (mean (SEM) 201.7 (15.4) $(\mathrm{n}=8)$ ) and colectomised cases of Crohn's disease between 111.0 and $319 \mathrm{pmol} /$

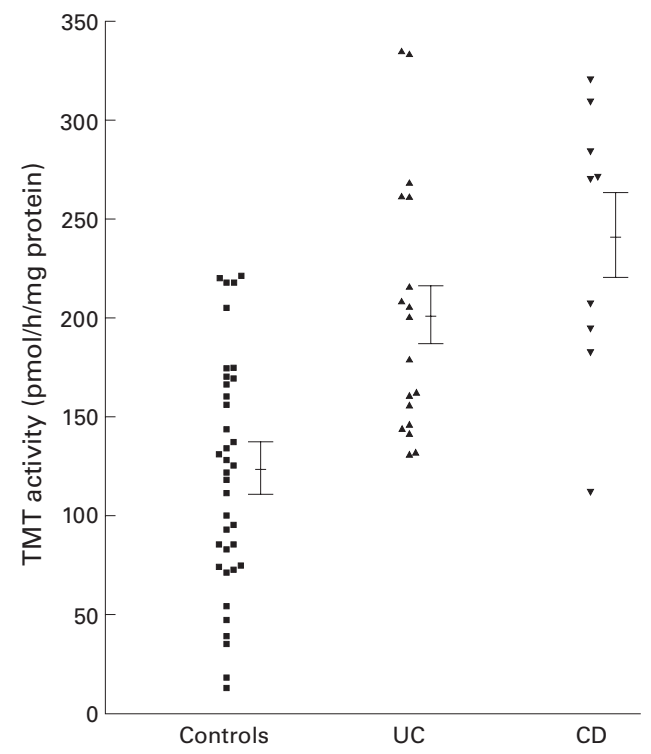

Figure 2 Thiol methyltransferase (TMT) activity of erythrocytes from blood donors, and from patients with ulcerative colitis (UC) or Crohn's disease (CD) treated by proctocolectomy. Mean values of colitis patients compared with controls, $p<0.001$.

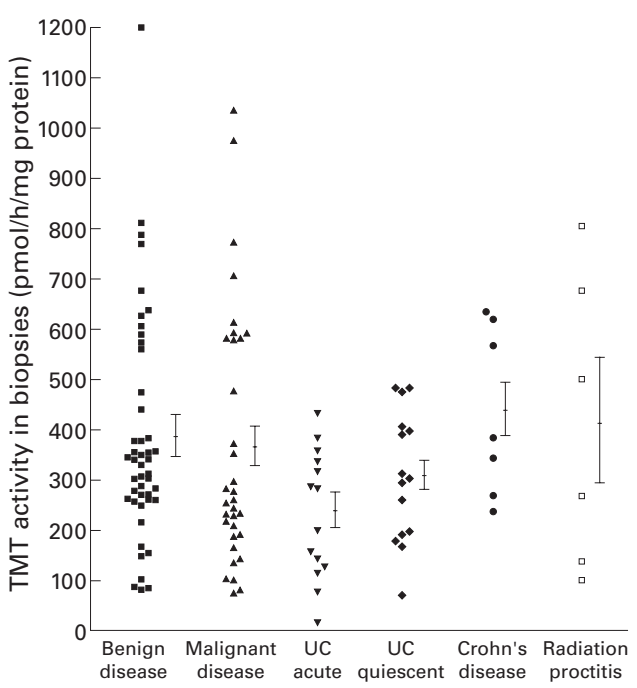

Figure 3 Thiol methyltransferase (TMT) activity of rectal biopsies at 10-15 cm. Acute ulcerative colitis (UC) compared with benign disease, $p<0.02$. Comparison of other groups were not significant.

hour/mg (237.8 (22.9) $(\mathrm{n}=9))$. Values in inflammatory bowel disease were significantly increased $(p<0.001)$ compared with healthy cases that had an intact colon.

Values of TMT activity in rectal biopsies (fig 3) were much higher than in erythrocyte membranes, in agreement with previous findings. ${ }^{25}$ Mean values for healthy controls were 379.7 (SEM 32.9) $(n=46)$, control colon cancer cases 363 (44.5) (n=33), acute UC 227 (33.7) $(\mathrm{n}=14)$, quiescent UC $301.8(33.2)(\mathrm{n}=15)$, active Crohn's disease $429(63.2)(n=7)$, and active radiation proctitis $406.7(118.7) \mathrm{pmol} /$ hour $/ \mathrm{mg}$ protein $(n=6)$. Analysis of variance (ANOVA) using STATA (Stata Statistical Software: release 5, 1997, Stata Corporation Texas, USA) detected no difference between the five groups of benign, malignant, acute UC, quiescent UC, and Crohn's disease $\left(\mathrm{F}_{5,115}=1.53\right.$, 
$\mathrm{p}=0.186$ ). Using Wald's test after ANOVA a difference was found comparing the benign group with the two UC groups together $(p=0.026)$. Values for active UC compared with healthy controls were significantly different $(p<0.02$; Student's test for unpaired samples) but no other values were significantly different from healthy controls or cancer control cases.

\section{Discussion}

TMT activity in the colonic mucosa has been reported as low ${ }^{21}$ or high, ${ }^{29}{ }^{30}$ with more recent studies $^{28}$ intermediary to these values. The method we used to assay TMT activity has previously been validated with regard to reproducibility and coefficient of variance. ${ }^{28}$ As the activity of TMT may vary along the length of the intestinal tract ${ }^{29} 30$ a fixed region for biopsy was chosen in which colitis usually manifests. Also of concern was whether biopsies, a composite tissue of immune and epithelial cells, would yield TMT activities reflective of isolated epithelial cells. ${ }^{28}$ This was found to be the case in healthy mucosa but remains untested in the inflamed mucosa. Immune cells are tolerant of high levels $(>1.5 \mathrm{mM})$ of hydrogen sulphide ${ }^{31}$ and may have considerable TMT activity. Apart from such a drawback, the methodology of the assay was carefully applied. $^{28}$

TMT activity of erythrocyte membranes in unoperated cases of UC has been found to be elevated in both active and quiescent colitis, the increase being significant in active UC but not Crohn's disease. ${ }^{22}{ }^{23}$ Current observations in operated cases of colitis replicated elevated TMT activity in erythrocyte membranes seen in unoperated cases of colitis ${ }^{22}{ }^{23}$ suggesting that factors causing elevation of TMT activity are present irrespective of the presence of the colon. One possible factor in unoperated cases could be a high intake of protein observed in $\mathrm{UC}^{32}$ and particularly foods rich in sulphur amino acids such as meat. ${ }^{33}{ }^{34}$ Sulphur amino acids can be a source of sulphur via endogenous sulphate production (unpublished observation) for sulphate reducing bacteria to produce sulphide, ${ }^{1}$ colonic levels of which are elevated in colitis patients. ${ }^{2-4}$ The foregoing explanation subsumes that TMT activity in erythrocytes is inducible. Other explanations could be that genetically programmed activity of TMT in erythrocytes may be different in colitis than in control cases. TMT activity of erythrocytes in non-colitis patients has a strong genetic relation ${ }^{35}$ which requires further study in cases of colitis.

Mucosal detoxification processes of sulphation and glutathione transferase activity ${ }^{19}$ are diminished in UC, particularly in active disease. Loss of sulphation was detected by noting diminished sulphation of paracetamol in rectal dialysate in vivo ${ }^{36}$ or in vitro by isolated colonocytes. $^{37}$ The diminished glutathione transferase activity was observed in human $\mathrm{UC}^{38}$ as well as in experimental animal colitis. ${ }^{39}$ Mucosal detoxification by methylation as now observed was diminished in moderate to severe UC but not quiescent colitis suggesting that the primary process of methylation was not impaired in our cases of UC. The state of TMT activity does not however entirely reflect the capacity to methylate as the process is dependent on a supply of SAM which in the assay was exogenously provided. In UC levels of endogenous SAM are low in colonocytes ${ }^{40}$ and methylation of DNA, which is also dependent on endogenous SAM, is low in the mucosa of UC. ${ }^{41}$ The potential for sulphide to cause mucosal metabolic damage is most likely to occur later in the development of the disease process of UC when production rates of sulphide may exceed the capacity of epithelial cells to detoxify the amount of sulphide produced in the colon.

Several lines of research ${ }^{19}{ }^{42}$ suggest that bacterial metabolism of sulphur may be a component of the disease process of UC. The activity of TMT in the colonic mucosa remains robust in early colitis without significant change from control cases, but a persistently elevated TMT activity in erythrocytes, shown in this and other studies, supports the view that other factors regulate TMT activity irrespective of the presence of the colon. Studies of genetic control of TMT activity in erythrocytes of colitis would be a worthwhile avenue of exploration.

The authors are indebted to Dr A Cummins, Mr J Moore, and Professor I Roberts-Thomson for study of their patients and to the chairman, committee, and members of the Ileostomy Association of South Australia for their cheerful cooperation in the study. Supported by a grant from the National Health and Medical Research Council of Australia.

1 Gibson GR, Cummings JH, MacFarlane GT. Growth and activities of sulphate reducing bacteria in gut contents of healthy subjects and patients with ulcerative colitis. FEMS Microbiol Ecol 1991;86:103-12.

2 Levine J, Ellis CJ, Furne JK, et al. Fecal hydrogen sulfide production in ulcerative colitis. Am f Gastroenterol 1998;93: $83-7$.

3 Florin THJ, Gibson GR, Neale G, et al. A role for sulfate reducing bacteria in ulcerative colitis. Gastroenterology 1990;98:A170.

4 Pitcher MCL, Beatty ER, Cummings JH. Salicylates inhibit bacterial sulphide production within the colonic lumen in ulcerative colitis. Gut 1995;37:A15.

5 Moore J, Babidge W, Millard S, Roediger WEW. Colonic Moore J, Babidge W, Millard S, Roediger WEW. Colonic
luminal hydrogen sulfide is not elevated in ulcerative colitis. Dig Dis Sci 1998;43:162-5.

6 Roediger WEW, Duncan A, Kapaniris O, et al. Reducing sulfur compounds of the colon impair colonocyte nutrition: mplications for ulcerative colitis. Gastroenterology 1993; 104:802-9.

7 Babidge W, Millard S, Roediger W. Sulfides impair short chain fatty acid $\beta$-oxidation at acyl-CoA dehydrogenase level in colonocytes: Implications for ulcerative colitis. $\mathrm{Mol}$ Cell Biochem 1998;181:117-24.

8 Roediger WEW, Duncan A, Kapaniris O, et al. Sulphide impairment of substrate oxidation in rat colonocytes: A biochemical basis for ulcerative colitis. Clin Sci 1993;85: 623-7.

9 Roediger WEW, Duncan A. 5-ASA decreases colonic sulfide formation: Implications for ulcerative colitis. Med Sci Res formation: Implic

10 Suarez FL, Furne JK, Springfield J, et al. Bismuth subsalicylate markedly decreases hydrogen sulfide release in the human colon. Gastroenterology 1998;114:923-9.

11 Fine KD, Lee EL. Efficacy of open-label bismuth subsalicylate for the treatment of microscopic colitis. Gastroenterology 1998;114:29-36.

12 Roediger WEW. Decreased sulphur aminoacid intake in ulcerative colitis. Lancet 1998;351:1555.

13 Pitcher MCL, Magee EAM, Beatty ER, Goddard M, Cummings JH. Can manipulation of dietary sulphate affect the activity of sulphate-reducing bacteria (SRB) in patients with ulcerative colitis. Gut 1996;38:A29.

14 Moore JWE, Millard S, Babidge W, et al. Hydrogen sulphide produces diminished fatty acid oxidation in the rat colon in vivo: implications for ulcerative colitis. Aust $N Z \exists$ J Surg 1997;67:245-9.

15 Christl SU, Eisner HD, Scheppach W, et al. Effect of hydrogen sulphide on cell proliferation of colonic mucosa. Gen sulphide on cell proliferat

16 Aslam M, Batten JJ, Florin THJ, Sidebotham RL, Baron JH Hydrogen sulphide induced damage to the colonic mucosal barrier in the rat. Gut 1992;33:S69. 
17 Mariggio MA, Pettini F, Fumarulo R. Sulfide influence on polymorphonuclear functions: a possible role for $\mathrm{Ca}^{2+}$ 393-404.

18 Roediger WEW, Babidge WJ. Nitric oxide effect on colonocyte metabolism: co-action of sulfides and peroxide. $\mathrm{Mol}$ Cell Biochem 2000;206:159-67.

19 Roediger WEW, Babidge W. Human colonocyte detoxification. Gut 1997;41:731-4.

20 Chiang PK, Gordon RK, Tal J, et al. S-Adenosylmethionine and methylation. FASEB $\mathcal{F}$ 1996;10:471-80.

21 Weisiger RA, Pinkus LM, Jakoby WB. Thiol S-methyltransferase: suggested role in detoxication of intestinal hydrogen sulfide. Biochem Pharmacol 1980;29: 2885-7.

22 Pitcher MCL, Beatty ER, Harris RM, et al. Sulfur metabolism in ulcerative colitis. Investigation of detoxification

Pizymes in peripheral blood. Dig Dis Sci 1998,43:2080-5.

Picton R, Eggo MC, Langman MJS, et al. Systemic sulphide detoxication in inflammatory bowel disease. Gut 1999;44: A31.

4 Picton R, Langman MJS, Singh S. Is there impaired detoxication of hydrogen sulphide in ulcerative colitis? Gut 1997; 42:A8

25 Truelove SC, Richards WCD. Biopsy studies in ulcerative colitis. BMF 1956;i:1315-18

26 Pazmino PA, Weinshilboum RM. Human erythrocyte phenol O-methyltransferase: radiochemical microassay an biochemical properties. Clin Chim Acta 1978;89:317-29.

27 Lowry OH, Rosebrough NJ, Faar AL, et al. Protein measurement with folin phenol reagent. F Biol Chem 1951; 193:265-75.

28 Babidge WJ, Millard SH, Roediger WEW. Thiol methyltransferase activity in colonocytes and erythrocyte membranes. F Clin Pathol 1995;48:641-4.

29 Pacifici GM, Romiti P, Santerini S, et al. S-methyltransferases in human intestine: differential distribution of the microsomal thiol methyltransferase and cytosolic methyltransferase along the human bowel. cytosolic methyltransferase
Xenobiotica 1993;23:671-9.

30 Singh S, Picton R, Langman MJS. Mechanisms for detoxifying hydrogen sulphide in the gastrointestinal tract. Gut 1997;40:A27.
31 Persson S, Claesson R, Carlsson J. Chemotaxis and degranulation of polymorphonuclear leukocytes in the degranulation of polymorphonuclear leukocytes in the
presence of sulfide. Oral Microbiol Immunol 1993;8:46-9.

32 Tragnone A, Valpiani D, Miglio F, et al. Dietary habits as risk factors for inflammatory bowel disease. Eur f Gastroenterol Hepatol 1995;7:47-51.

33 Geypens B, Claus D, Evenepoel P, et al. Influence of dietary protein supplements on the formation of bacterial metabolites in the colon. Gut 1997;41:70-6.

34 Magee EAM, Cummings JH. The contribution of dietary protein from meat to faecal sulphide excretion. Gut 1997;40:A27.

35 Keith RA, Vanloon J, Wussow LF, et al. Thiol methylation pharmacogenetics: heritability of human erythrocyte thiol methyltransferase activity. Clin Pharmacol Ther 1983;34: 521-8.

36 Ramakrishna BS, Roberts-Thomson IC, Pannall PR, et al. Impaired sulphation of phenol by the colonic mucosa in quiescent and active ulcerative colitis. Gut 1991;32:46-9.

37 Roediger WEW. The role of sulphur metabolism and mercapto fatty acids in the aetiology of ulcerative colitis. In: Goebell $\mathrm{H}$, Malchow $\mathrm{H}$, Ewe $\mathrm{K}$, et al, eds. Inflammatory bowel disease. Progress in basic research and clinical implications. Lancaster: Kluwer Acad Publications, 1991:17-27.

38 Hertervig E, Nilsson A, Seiddegard J. The expression of glutathione transferase $\mu$ in patients with inflammatory bowel disease. Scand 7 Gastroenterol 1994;29:729-35.

39 Clapper ML, Adrian RH, Pfeiffer GR, et al. Depletion of colonic detoxication enzyme activity in mice with dextran sulphate sodium-induced colitis. Aliment Pharmacol Ther 1999;13:389-96.

40 Thiede C, Bayerdorffer E, Thiede H-M, et al. Quantification of the essential methyl group donor S-adenosylmethionine in human colorectal mucosa of patients with inflammatory bowel disease (IBD) and colorectal adenomas. Gastroenterology 1995;108:A546.

41 Cravo M, Gloria L, De Sousa S, et al. Folate status, DNA methylation and colon cancer risk in inflammatory bowel disease. Clin Nutr 1995;14:50-3.

42 Pitcher MCL, Cummings JH. Hydrogen sulphide: a bacterial toxin in ulcerative colitis. Gut 1996;39:1-4 